\title{
Salivary levels of Tumour Necrosis Factor-alpha in patients with recurrent aphthous stomatitis
}

\author{
Asier Eguia-del Valle, Rafael Martinez-Conde-Llamosas, Jose López-Vicente, Agurne Uribarri-Etxebarria, \\ José-Manuel Aguirre-Urizar
}

Oral Medicine. Faculty of Medicine and Dentistry. University of the Basque Country

Correspondence:

Barrio Sarriena $s / n$

Leioa CP 48940

(Vizcaya) (Spain)

aeguiadelvalle@yahoo.es

Received: 03/01/2010

Accepted: 21/03/2010

\author{
Eguia-del Valle A, Martinez-Conde-Llamosas R, López-Vicente J, Uriba- \\ rri-Etxebarria A, Aguirre-Urizar JM. Salivary levels of Tumour Necrosis \\ Factor-alpha in patients with recurrent aphthous stomatitis. Med Oral Pa- \\ tol Oral Cir Bucal. 2011 Jan 1;16 (1):e33-6. \\ http://www.medicinaoral.com/medoralfree01/v16i1/medoralv16ilp33.pdf

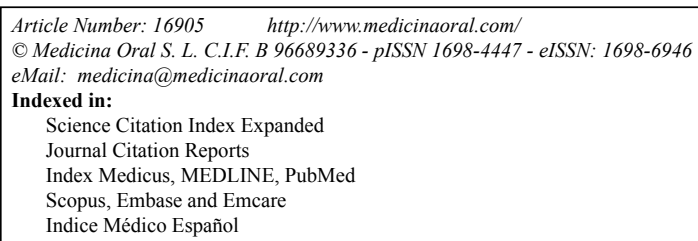

\begin{abstract}
Objetives: Recurrent aphthous stomatitis (RAS) is a common pathology of the oral mucosa with a complex and multifactorial etiology. Tumour Necrosis Factor-alpha (TNF $\alpha)$ is a cytokine with an important but not well-known role in the development of new lesions in RAS patients. Modifications of salivary levels of TNF $\alpha$ in RAS patients during the active periods of the disease have been measured in this work. The possible implication of TNF $\alpha$ in RAS etiology is also discussed. Study design: The study group was composed of 20 patients previously diagnosed with RAS and randomly selected. As a control group 10 healthy patients were also randomly selected. In both groups a TNF $\alpha$ assessment was carried out in non stimulated saliva. All the patients in the study group presented active lesions at the moment of the salivary sample collection. Values oscillating between 0 and $8.1 \mathrm{pg} / \mathrm{ml}$ were considered as normal. Results: Salivary TNF $\alpha$ levels are 2 to 5 times higher in RAS patients than those of healthy patients. Conclusions: TNF $\alpha$ has a possible implication in the RAS etiology and it may also have an important role in the search of new treatments for this disease.
\end{abstract}

Key words: Recurrent aphthous stomatitis, Tumour Necrosis Factor, oral ulcers, cytokines.

\section{Introduction}

Recurrent aphthous stomatitis (RAS) is one of the most common diseases of the oral mucosa (1-3). A high number of research works have been carried out trying to discover the cause of this prevalent disease. Nevertheless, the etiology of RAS still remains unknown (1-3). Different authors are in controversy about the complex pathogenesis of the disease (1-3). One of the most discussed aspects is the exact role of different pre- disposing factors such as genetic, immunologic, microbiologic, alimentary, hormonal, emotional or traumatic factors. Actually there is not a definitive explanation for the pathogenesis of RAS able to justify the implication of all of them (1-3).

The most accepted hypothesis about the etiology of the disease among the authors is based on the existence of a predisposition is some patients with a light immunitary alteration of a possible genetic origin. In 
such patients, the presence of a local and/or systemic stimulation causes the transformation of oral mucosal cells into the target of the uncontrolled action of lymphocytes, monocytes and neutrophils. This would lead to the destruction of oral mucosal cells, the liberation of acute inflammation mediators and the development of an aphthous ulcer (4-6).

The ulcerative process is initiated by an unknown antigenic stimulation of the mucosal keratinocytes which leads to t-lymphocyte stimulation, the liberation of citokynes such as TNF- $\alpha$ and different interleukins, and the migration of other lymphocytes, neutrophils and Langerhans cells. This also leads to an overexpression of Vascular Cell Adhesion Molecules (VCAM-1, Selectine E) and Intercellular Adhesion Molecules (ICAM-1) causing the accumulation of lymphocytes and the local lymphocytic invasion of the epithelium. Some cytokines like TNF- $\alpha$ could stimulate the expresión of major histocompatibility complex class I and II antigens in epithelial basal cells. These cells are recognized by t-lymphocites triggering a citotoxic response and causing the ulceration of the mucosa (4-6).

At present, TNF $\alpha$ is considered to be one of the most important cytokines implied in the development of new lesions in RAS patients. Several studies $(7,8)$ have reported an increase in salivary and serological TNF $\alpha$, specially during the active phase of the disease. Nevertheless, the actual cause of this increase has not been clarified to date. In the present work we have tried to confirm whether salivary TNF $\alpha$ is increased during the acute phase of RAS in patients in our vicinity.

\section{Materials and Methods}

The present study was carried out on 20 randomly selected patients previously diagnosed with RAS. All of them were selected from the Oral Medicine Department and Dental School of the University of the Basque Country. To set up a control group, 10 healthy patients were also randomly selected. All the patients signed an informed consent.

After formal signing and consent, in all of them a salivary $\mathrm{TNF} \alpha$ measurement was performed in samples of whole non stimulated saliva. Samples were obtained asking the patient to spit into a calibrated test tube during five minutes. All the samples were collected between 9 and 12 A.M. and after one our or more time since the last food intake. At this moment all the patients presented active lesions in ulcerative phase.

After cooling for 10 minutes, the samples were frozen $\left(-25^{\circ} \mathrm{C}\right)$ and processed. TNF $\alpha$ determination was carried out employing immunoassay and quimioluminiscence techniques. The Immulite-TNF $\alpha \AA$ test (Diagnostic Product Corporation, Dipesa SA, Spain) was employed for the measurement of TNF $\alpha$ levels.

The salivary samples were cultivated in the presence of specific anti-TNF $\alpha$ antigen alter a controlled defrost and centrifugation. The levels of TNF $\alpha$ were determined with an automatic analysis unit Inmulite $2000 \AA$ (Diagnostic Product Corporation, Dipesa SA, Spain) after the application of a quimioluminiscent substrate. Values between 0 and $8,1 \mathrm{pg} / \mathrm{ml}$ were considered within a normality range $(7,11)$.

\section{Results}

The mean level of salivary TNF $\alpha$ was $53,6 \mathrm{pg} / \mathrm{ml}$ (range $35,1-111$ ) in RAS patients and $26 \mathrm{pg} / \mathrm{ml}$ (range 10,2-36,9) in control group. Statistically salivary TNFa levels were significantly higher $(\mathrm{p} \leq 0,01)$ in RAS patients. Tables 1,2 and figure 1 show in detail the results of the analyses in both groups of patients.

Table 1. Salivary TNF $\alpha$ levels in RAS patients.

\begin{tabular}{cc} 
Patients EAR & TNFa $(\mathrm{pg} / \mathrm{ml})$ \\
\hline Sample 1 & 35,4 \\
Sample 2 & 38,6 \\
Sample 3 & 35,1 \\
Sample 4 & 45,1 \\
Sample 5 & 80,8 \\
Sample 6 & 111 \\
Sample 7 & 56,9 \\
Sample 8 & 42,3 \\
Sample 9 & 71,4 \\
Sample 10 & 78,8 \\
Sample 11 & 39,5 \\
Sample 12 & 42,5 \\
Sample 13 & 43,7 \\
Sample 14 & 36,9 \\
Sample 15 & 39,6 \\
Sample 16 & 55,7 \\
Sample 17 & 49,6 \\
Sample 18 & 50 \\
Sample 19 & 43 \\
Sample 20 & 76
\end{tabular}

Table 2. Salivary TNF $\alpha$ levels in control patients.

\begin{tabular}{cc} 
Control Samples & TNF $\alpha(\mathrm{pg} / \mathrm{ml})$ \\
\hline Control 1 & 29,6 \\
Control 2 & 26,7 \\
Control 3 & 17,3 \\
Control 4 & 10,2 \\
Control 5 & 31,8 \\
Control 6 & 27,6 \\
Control 7 & 22,4 \\
Control 8 & 30,3 \\
Control 9 & 27,5 \\
Control 10 & 36,9
\end{tabular}




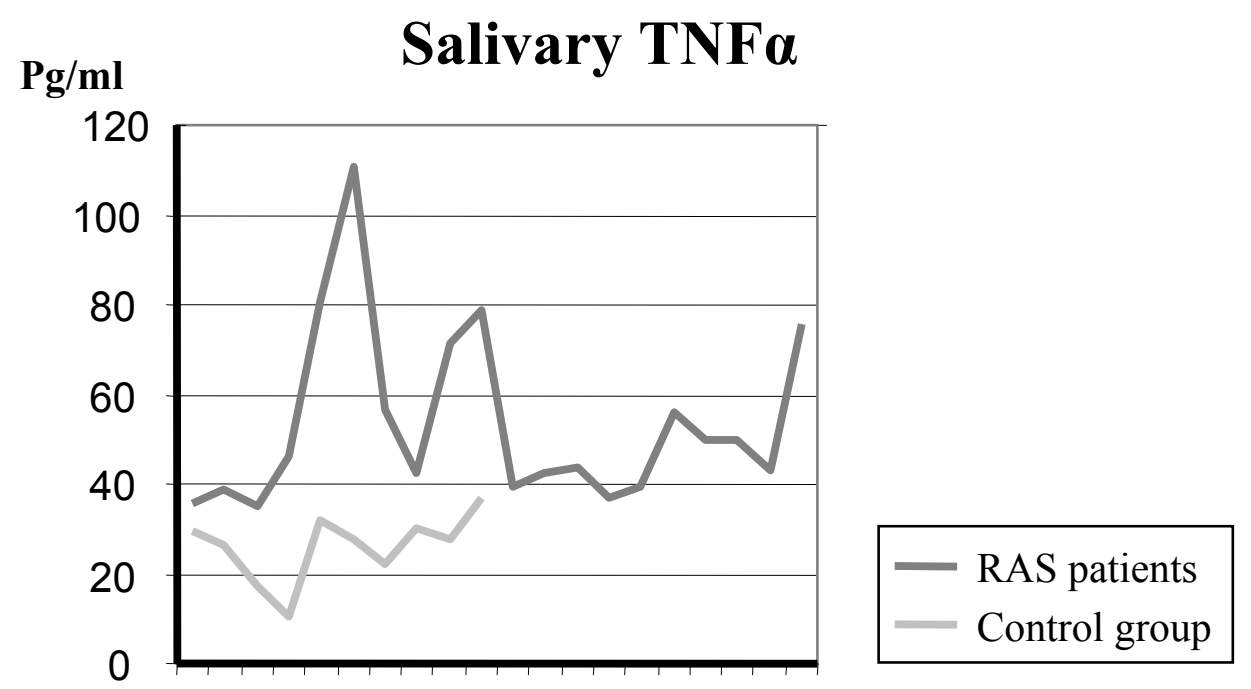

Fig. 1. Salivary TNF $\alpha$ in RAS patients and control patients.

\section{Discussion}

TNF is a proinflammatory cytokine found in patients with cachexia and also whe studying the hemorrhagic necrosis in animal and human neoplasms $(12,13)$. This cytokine is produced by monocytes, lymphocytes, NK cell and even by some human tumoral cells. The TNF also acts as a mediator of endotoxic shock and plays an important role in some autoimmune diseases, certain kinds of meningitis, HIV infection and cachexia $(12,13)$.

The exact role that TNF plays in the etiology or RAS is not well-known. Its contribution to the pathogenesis of the disease is borne out by two facts: high levels of TNF are detected in the first stages of oral ulcerations and some drugs like thalidomide or pentoxifylline with an anti-TNF action, have a high efficacy in the treatment of RAS and other ulcerative diseases such as Adamantiades-Behçet disease (7,14-17).

Different authors $(7,8)$ have observed increased levels of TNF $\alpha$ in serum and in saliva of RAS patients, especially in the active phase of the disease. In our study, salivay TNF $\alpha$ was 2 to 5 times higher in patients with active lesions of RAS compared with controls. This result underlines the importance of this cytokine in the pathogenesis of RAS.

The complex pathogenesis of RAS is probably initiated by an endogenous or exogenous antigenic stimulation of oral mucosal keratinocytes. This causes the production of different interleukins by stimulation of oral lymphocytes. TNF $\alpha$ is one of these interleukins of a great importance in the beginning of the inflammatory process. This stimulation is the first step of a multistage process which lead to the activation $\mathrm{f}$ cytotoxic $\mathrm{t}$-cells and neutrophils, the necrosis of the epithelium and finally the development of an aphthous lesion.
Research workers in this field have demonstrated efficacy in the prevention and treatment of RAS with some drugs that are able to reduce the production of TNF such as levamisol, thalidomide or pentoxifylline (1417). Probably their efficacy in the treatment of RAS is based in this inhibitory action.

There is not a definitive therapy for RAS and certain of drugs used in the treatment also have severe secondary effects. The search for new drugs with a more specific TNF inhibitory action and less side effects could be a new approach in the treatment of this disease in the future.

Guimaraes and cols. (18) have related the high production of some cytokines, such as TNF $\alpha$, IL-1, IL-10 or IL-6 in RAS patients to some genetic polymorphisms. This fact could explain the family history frequently observed in some RAS patients.

Salivary determination is an easy and safe process that allows to measure the $\mathrm{TNF} \alpha$ level modification in the same patient in different moments. A sample of $0.2 \mathrm{ml}$. of saliva is enough to make this determination.

We have not found other studies in the literature that determine the normal range in the salivary $\mathrm{TNF} \alpha$ assessment. In most of the research papers reviewed $(7,11)$ serological normal range is employed $(0-8,1 \mathrm{pg} / \mathrm{ml})$. However, we think that this range should be reexamined for salivary samples.

The development of new drugs specifically designed to block the TNF $\alpha$ could be a new approach in the treatment of RAS, with a higher efficacy and safety compared with those used at present $(17,19,20)$. 


\section{References}

1. Ship JA. Recurrent aphthous stomatitis. An update. Oral Surg Oral Med Oral Pathol Oral Radiol Endod. 1996;81:141-7.

2. Porter SR, Scully C, Pedersen A. Recurrent aphthous stomatitis. Crit Rev Oral Biol Med. 1998;9:306-21.

3. Rioboo-Crespo Mdel R, Planells-del Pozo P, Rioboo-García R. Epidemiology of the most common oral mucosal diseases in children. Med Oral Patol Oral Cir Bucal. 2005;10:376-87.

4. Pedersen A, Hougen HP, Kenrad B. T-lymphocyte subsets in oral mucosa of patients with recurrent aphthous ulceration. J Oral Pathol Med. 1992;21:176-80.

5. Ship JA, Chavez EM, Doerr PA, Henson BS, Sarmadi M. Recurrent aphthous stomatitis. Quintessence Int. 2000;31:95-112.

6. Scully C, Gorsky M, Lozada-Nur F. The diagnosis and management of recurrent aphthous stomatitis: a consensus approach. J Am Dent Assoc. 2003;134:200-7.

7. Boras VV, Lukac J, Brailo V, Picek P, Kordić D, Zilić IA. Salivary interleukin-6 and tumor necrosis factor-alpha in patients with recurrent aphthous ulceration. J Oral Pathol Med. 2006;35:241-3.

8. Natah SS, Häyrinen-Immonen R, Hietanen J, Malmström M, Konttinen YT. Immunolocalization of tumor necrosis factor-alpha expressing cells in recurrent aphthous ulcer lesions (RAU). J Oral Pathol Med. 2000;29:19-25.

9. Tirelli AS, Colombo C, Torresani E, Cariani L, Arnaboldi E, Conese $\mathrm{M}$. Validation of an automated sensitive immunoassay for quantitation of cytokines in the sputum of cystic fibrosis patients. Clin Chem Lab Med. 2007;45:108-11.

10. Berthier F, Lambert C, Genin C, Bienvenu J. Evaluation of an automated immunoassay method for cytokine measurement using the Immulite Immunoassay system. Clin Chem Lab Med. 1999;37:593-9.

11. Evereklioglu C, Er H, Türköz Y, Cekmen M. Serum levels of TNF-alpha, sIL-2R, IL-6, and IL-8 are increased and associated with elevated lipid peroxidation in patients with Behçet's disease. Mediators Inflamm. 2002;11:87-93.

12. Saini A, Al-Shanti N, Stewart CE. Waste management - cytokines, growth factors and cachexia. Cytokine Growth Factor Rev. 2006; 17:475-86.

13. Brabers NA, Nottet HS. Role of the pro-inflammatory cytokines TNF-alpha and IL-1beta in HIV-associated dementia. Eur J Clin Invest. 2006;36:447-58.

14. Sun A, Wang JT, Chia JS, Chiang CP. Levamisole can modulate the serum tumor necrosis factor-alpha level in patients with recurrent aphthous ulcerations. J Oral Pathol Med. 2006;35:111-6.

15. Eguia A, Villarroel M, Martínez-Conde R, Echebarría MA, Aguirre JM. Adamantiades-Behçet disease: an enigmatic process with oral manifestations. Med Oral Patol Oral Cir Bucal. 2006;11:E6-11. 16. García Callejo FJ, Orts Alborch MH, Morant Ventura A, Segarra Cortés P, Marco Algarra J. [Recurrent aphthous stomatitis and clinical response to pentoxifylline]. Acta Otorrinolaringol Esp. 1999;50:671-3.

17. Vujevich J, Zirwas M. Treatment of severe, recalcitrant, major aphthous stomatitis with adalimumab. Cutis. 2005;76:129-32.

18. Guimarães AL, Correia-Silva Jde F, Sá AR, Victória JM, Diniz MG, Costa Fde O, et al. Investigation of functional gene polymorphisms IL-1beta, IL-6, IL-10 and TNF-alpha in individuals with recurrent aphthous stomatitis. Arch Oral Biol. 2007;52:268-72.

19. Okada AA. Behçet's disease: general concepts and recent advances. Curr Opin Ophthalmol. 2006;17:551-6.

20. Hale S, Lightman S. Anti-TNF therapies in the management of acute and chronic uveitis. Cytokine. 2006;33:231-7.

\section{Acknowledgments}

The authors want to thank Dr. David Hallett for his great help in the translation of this work. 